\title{
Triazole Fungicides Sensitivity of Sclerotinia homoeocarpa in Korean Golf Courses
}

\author{
Ji Won Lee, Jihye Choi, and Jin-Won Kim* \\ Department of Environmental Horticulture, University of Seoul, Seoul 02504, Korea
}

(Received on June 5, 2017; Revised on September 19, 2017; Accepted on September 20, 2017)

Chemical management of dollar spot in turf may lead to the development of Sclerotinia homoeocarpa populations with reduced fungicide sensitivity. The objective of this study was to investigate resistance of $S$. homoeocarpa isolates to triazole fungicides and to test crossresistance among three triazole fungicides. A total of 66 isolates of $S$. homoeocarpa were collected from 15 golf courses across Korea, and tested via in vitro sensitivity assay against hexaconazole, propiconazole and tebuconazole. $\mathrm{EC}_{50}$ values of the isolates to these fungicides were distributed in the range of 0.001-1.1 a. i. $\mu \mathrm{g} \mathrm{ml}^{-1}$. Based on the $\mathbf{E C}_{50}$ values, twelve representative strains were selected as sensitive isolates including control and insensitive isolates with respect to each fungicide. At a concentration of 0.1 a. $i$. $\mu \mathrm{g} \mathrm{ml}^{-1}$ for all fungicides, the selected strains were distinguished as sensitive or resistant isolates with the mycelial growth inhibition rate of $50 \%$ as the criterion. The $\mathrm{EC}_{50}$ values of resistant strains exposed to hexaconazole, propiconazole and tebuconazole were 20-50 times, 50-70 times, and 77 times greater, respectively, than that of the control strains. Two isolates of $S$. homoeocarpa S0-41 and Sh142-1 showed sensitivity toward all the fungicides used, while two other isolates Sh7-5-1 and Sh2-1-1 showed resistance to all fungicides. Each isolate showed similar resistance to the three types of triazole fungicides, whereby cross-resistance of isolates was confirmed in the present study; all three triazole fungicide combi-

\footnotetext{
*Corresponding author.

Phone) +82-6490-2690, FAX) +82-6490-2684

E-mail)jwkim@uos.ac.kr

(c) This is an Open Access article distributed under the terms of the Creative Commons Attribution Non-Commercial License (http:// creativecommons.org/licenses/by-nc/4.0) which permits unrestricted noncommercial use, distribution, and reproduction in any medium, provided the original work is properly cited.
}

Articles can be freely viewed online at www.ppjonline.org. nations displayed significant correlation coefficients equivalent to or greater than 0.8 .

Keywords : dollar spot, fungicides sensitivity, golf courses, triazole, Sclerotinia homoeocarpa

Handling Associate Editor : Lee, Yong Hoon

Dollar spot, caused by Sclerotinia homoeocarpa, is a common and persistent disease of cool-and warm-season turfgrass species occurring in golf courses in South Korea, North America, Europe, Japan and elsewhere. Chemical preventive measures employing fungicides are in use for the prevention of dollar spot. Nevertheless, due to repetitive usage of these fungicides, the manifestation of fungicide resistant strains is increasingly reported. Appearance of resistant isolates to the fungicides containing heavy metal additives was reported as early as in the late 1960s (Cole et al., 1968; Massie et al., 1968). Benzimidazole fungicides experienced numerous reports of occurrences of resistant isolates in the early 1970s soon after its registration (Burpee, 1997; Detweiler et al., 1983; Warren et al., 1974). Among the translocating fungicide, a dicarboxamide fungicide was reported in 1980s (Detweiler et al., 1983), and a demethylation inhibitor (DMI) fungicide was too highlighted in 1990s that the appearance of resistant isolates was occurred (Vargas et al., 1992). Since the first report of the resistant isolates of DMI fungicides on a dollar spot was filed by Vargas et al. (1992), a lot of research reports on the resistance of DMI fungicides in many countries such as the United States, Europe, and Canada (Burpee, 1997; Golembiewski et al., 1995; Hsiang et al., 2007; Jo et al., 2006; Miller et al., 2002; Mocioni et al., 2001; Ok et al., 2011; Popko et al., 2012) have been published. In South Korea, appearance of resistance to propiconazole has been reported (Shim et al., 2001).

Same class of fungicides usually show cross-resistance, 
but cases of not exhibiting cross-resistance or showing weak correlations have been reported for DMI fungicides (Hsiang et al., 1997; Leroux, 1992; Miller et al., 2002; Robbertse et al., 2001). The maiden attempt to study the cross-resistance to DMI on grass dollar spot was by Doney and Vinceli (1993), and research reports on cross-resistance of triazole fungicides has been well documented (Golembiewski et al., 1995; Hsiang et al., 1997; Miller et al., 2002; Ok et al., 2011).

The aims of the present research were to (i) identify modified sensitivity of $S$. hoemoeocarpa isolates in golf courses treated with triazole fungicides and (ii) investigate the cross-resistance of $S$. hoemoeocarpa isolates towards three triazole fungicides i.e., hexaconazole, propiconazole and tebuconazole, which are typically used for the prevention of dollar spot in the fields.

\section{Materials and Methods}

Collection and isolation of $S$. homoeocarpa. S. homoeocarpa isolates were collected from golf courses green, tee and fairway exhibiting dollar spots across ten golf courses in South Korea. Isolation was made by collecting holecup sized cylindrical turfgrass patches taken from ten golf courses in Korea. Two hundred and sixty-five isolates of $S$. homoeocarpa were collected from four different species of turfgrasses: 161 isolates from creeping bentgrass, 67 isolates from Kentucky bluegrass, 21 isolates from perennial ryegrass and 16 isolates from zoysiagrass (Table 1). The isolates were sampled in spring and fall of 2014 and 2015. Of the 265 isolates, sixty strains of $S$. homoeocarpa were chosen for use in the study by selecting only one strain per diseased patch in the sample and additional six strains were obtained from the Korea Turfgrass Research Institute (KTRI) (Table 2).

Each isolate was picked up from the margins of the infection center on symptomatic leaf blades as described by Jo et al. (2006). Individual leaf blades infected within the dollar spot showing distinctive brown edge at the rim were surface disinfected in $75 \% \mathrm{EtOH}$ and $1 \%$ sodium hypochlorite solution, and rinsed three times using sterilized water. The disinfected leaf blades were dried on a sterilized filter paper prior to inoculation of the fungi on water agar (WA) and stored at $25^{\circ} \mathrm{C}$ for $48 \mathrm{~h}$ under cycles of $12 \mathrm{~h}$ light $/ 12 \mathrm{~h}$ darkness.

Mycelium formed from the section was isolated and transferred to potato dextrose agar (PDA; Difco, USA). After 7 days of inoculation on PDA, S. homoeocarpa isolates were identified based on morphological features and by comparison to reference isolates. Pure cultures of $S$. homoeocarpa were obtained by subculturing hyphae from the edge of an actively growing colony and subsequently transferred to PDA plates.

In vitro sensitivity assay. In vitro sensitivity assays of $S$. homoeocarpa isolates to triazole fungicides including hexaconazole SC (a. i. cont. $2 \%$ ), propiconazole EC (a. i. cont. 25\%), and tebuconazole SC (a. i. cont. 20\%) were conducted. Each triazole fungicide was diluted to prepare five different concentrations containing 10.0, 1.0, 0.1, 0.01, and 0.001 a. i. $\mu \mathrm{g} \mathrm{ml}^{-1}$.

One milliliter of each diluted fungicide was added to 599

Table 1. Collection sites, Host plants, and the number of Sclerotinia homoeocarpa isolates

\begin{tabular}{|c|c|c|c|}
\hline Golf courses & Location & Host & No. of isolates \\
\hline \multirow[t]{2}{*}{ Hallasan C. C. } & Jeju-si, Jeju do & Agrostis palustris & 25 \\
\hline & & Poa pratensis & 11 \\
\hline Blueone bomun C. C. & Gyeongju-si, Gyoengsangbuk-do & A. palustris & 37 \\
\hline Castlepine G. C. & Yeoju-si, Gyeonggi-do & P. pratensis & 8 \\
\hline \multirow[t]{2}{*}{ Jadepalace G. C. } & Chuncheon-si, Gangwon-do & A. palustris & 16 \\
\hline & & P. pratensis & 4 \\
\hline \multirow[t]{3}{*}{ Vivaldipark C. C. } & Hongcheon-gun, Ganwon-do & A. palustris & 26 \\
\hline & & P. pratensis & 10 \\
\hline & & Lolium perenne & 21 \\
\hline Pohang C. C. & Pohang-si, Gyeongsangbuk-do & A. palustris & 16 \\
\hline Gaya C. C. & Gimhae-si, Gyoengsangnam-do & A. palustris & 12 \\
\hline Seowonhills C. C. & Paju, Gyeonggi-do & P. pratensis & 34 \\
\hline Rexfield C. C. & Yeoju-si, Gyeonggi-do & Zoysia japonica & 16 \\
\hline Ecoland G. C. & Jeju-si, Jeju island & A. palustris & 29 \\
\hline Total number of isolates & & & 265 \\
\hline
\end{tabular}


Table 2. The date of isolation, collected golf courses, history of triazole fungicides use, host, and the number of isolates of Sclerotinia homoeocarpa used in this study

\begin{tabular}{|c|c|c|c|c|c|}
\hline No. & Golf courses & Triazole exposure $^{a}$ & $\operatorname{Host}^{\mathrm{b}}$ & No. of isolates & The date of isolation \\
\hline Sh1 & Hallasan C.C. & $\mathrm{H}, \mathrm{T}, \mathrm{P}$ & $\mathrm{CB}, \mathrm{KB}, \mathrm{PR}$ & 5 & 2014. 4. \\
\hline Sh2 & Blueonebomun C.C. & $\mathrm{H}, \mathrm{T}, \mathrm{P}$ & $\mathrm{CB}$ & 4 & 2014. 5 . \\
\hline Sh3 & Castlepine G.C. & $\mathrm{H}, \mathrm{T}, \mathrm{P}$ & KB & 1 & 2014. 6 . \\
\hline Sh4 & Jadepalace G.C. & $\mathrm{H}, \mathrm{T}, \mathrm{P}$ & $\mathrm{CB}$ & 1 & 2014. 6 . \\
\hline Sh5 & Vivaldipark C.C. & $\mathrm{H}, \mathrm{T}, \mathrm{P}$ & $\mathrm{CB}, \mathrm{KB}, \mathrm{PR}$ & 5 & 2014. 7 . \\
\hline Sh6 & Pohang C.C. & $\mathrm{T}$ & $\mathrm{CB}$ & 3 & 2014. 7 . \\
\hline $\mathrm{Sh} 7$ & Vivaldipark C.C. & $\mathrm{H}, \mathrm{T}, \mathrm{P}$ & $\mathrm{CB}$ & 5 & 2015. 5 . \\
\hline Sh8 & Gaya C.C. & $\mathrm{P}$ & $\mathrm{CB}$ & 4 & 2015. 5 . \\
\hline Sh9 & Seowonhills C.C. & $\mathrm{H}$ & KB & 8 & 2015. 6 . \\
\hline Sh10 & Hallasan C.C. & $\mathrm{H}, \mathrm{T}, \mathrm{P}$ & $\mathrm{CB}, \mathrm{KB}$ & 5 & 2015. 6 . \\
\hline Sh11 & Vivaldipark C.C. & $\mathrm{H}, \mathrm{T}, \mathrm{P}$ & KB & 2 & 2015. 6 . \\
\hline Sh12 & Jadepalace G.C. & $\mathrm{H}, \mathrm{T}, \mathrm{P}$ & $\mathrm{CB}, \mathrm{KB}$ & 6 & 2015. 6 . \\
\hline Sh13 & Rexfield C.C. & $\mathrm{H}, \mathrm{T}, \mathrm{P}$ & $\mathrm{Z}$ & 5 & 2015. 6 . \\
\hline Sh14 & Ecoland G.C. & Non & $\mathrm{CB}$ & 6 & 2015. 7. \\
\hline $\mathrm{S} 0-7^{\mathrm{c}}$ & New Seoul C.C. & $-{ }^{d}$ & KB & 1 & 2009.8 . \\
\hline $\mathrm{S} 0-11^{\mathrm{c}}$ & Nam Seoul C.C. & - & KB & 1 & 2009. 8. \\
\hline $\mathrm{S} 0-21^{\mathrm{c}}$ & Vivaldipark C.C. & - & $\mathrm{CB}$ & 1 & 2009.11. \\
\hline $\mathrm{S} 0-41^{\mathrm{c}}$ & Grand C.C. & - & $\mathrm{CB}$ & 1 & 2004. 6 . \\
\hline S0-42 & Iljuck Sunvalley C.C. & - & $\mathrm{CB}$ & 1 & 2008. 6 . \\
\hline S0-43 & Asiad C.C. & - & $\mathrm{CB}$ & 1 & 2008. 5. \\
\hline Total & & & & 66 & \\
\hline
\end{tabular}

${ }^{\mathrm{a}}$ History of triazole fungicides exposure; $\mathrm{H}=$ Hexaconazole, $\mathrm{T}=$ Tebuconazole, $\mathrm{P}=$ Propiconazole.

${ }^{b}$ Host; $\mathrm{CB}=$ creeping bentgrass, $\mathrm{KB}=$ Kentucky bluegrass, $\mathrm{PR}=$ Perennial ryegrass, $\mathrm{Z}=$ Zoysiagrass.

'Obtained from the Korea Turfgrass Research Institute (KTRI).

${ }^{\mathrm{d}}$ Unknown history of triazole fungicides exposure.

$\mathrm{ml}$ of PDA cooled to $50-55^{\circ} \mathrm{C}$ and evenly mixed using a magnetic stirrer. The fungicide-amended PDA was poured into Petri-dishes ( $9 \mathrm{~cm}$ in diameter).

S. homoeocarpa isolates were inoculated at $25^{\circ} \mathrm{C}$ and incubated for 2-3 days under $12 \mathrm{~h} \mathrm{light/12} \mathrm{h}$ dark cycles. Agar plugs ( $5 \mathrm{~mm}$ in diameter) from the margins of actively growing $S$. homoeocarpa cultures were transferred to the center of fungicide-amended PDA plates. For each fungicide treatment, three replicates of fungicide amended PDA plates and three additional PDA petri-dishes without fungicide (control) were used. All fungal isolates were incubated at $25^{\circ} \mathrm{C}$. Four radial points located approximately $90^{\circ}$ apart on the actively growing $S$. homoeocarpa mycelium colonies were marked, and the growth of mycelium in outer radial directions was measured within $48 \mathrm{~h}$ following transfer.

To determine the rate of mycelium growth inhibition (\%), length of mycelium growth of $S$. homoeocarpa isolates were also measured.

Fifty percent effective concentration $\left(\mathrm{EC}_{50}\right)$ values of $S$. homoeocarpa isolates was estimated based on their rela- tive mycelium growth on the control PDA and fungicide amended PDA plates. The fungicide concentrations were log-transfermed and the $\mathrm{EC}_{50}$ values were calculated from the linear regression model generated. Linear regression was used to determine the relationship between mycelium growth and fungicide concentrations using the PROC PROBIT (SAS 9.4: SAS Institute, Cary, NC) software.

Cross-resistance. Using the $\log \mathrm{EC}_{50}$ value of $66 \mathrm{~S}$. homoeocarpa isolates against the registered fungicides, the relationship between the 3 triazole fungicides was analyzed via paired comparison. Through these inter relational results, cross-resistance was analyzed for hexaconazolepropiconazole, hexaconazole-tebuconazole, propiconazoletebuconazole fungicide combinations by calculating the correlation coefficients of these three fungicides.

\section{Results}

Isolate sensitivity to triazole fungicides. Sensitive and resistant isolates were not clearly distinguished and showed 


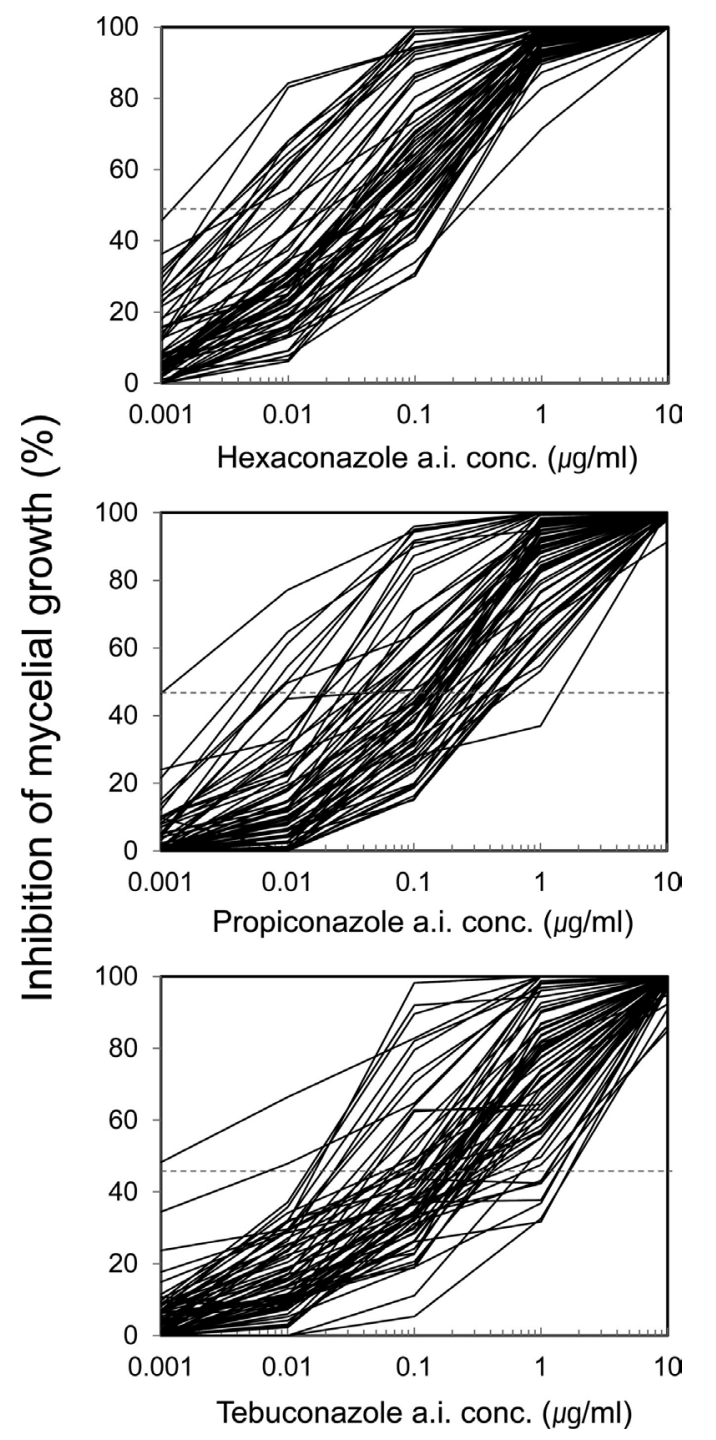

Fig. 1. Differential responses of 66 isolates of Sclerotinia homoeocarpa to hexaconazole, propiconazole, and tebuconazole. The isolates were grown on PDA with various concentrations of hexaconazole, propiconazole, and tebuconazole for two days at $25^{\circ} \mathrm{C}$ in darkness.

quantitatively random distribution (Fig. 1). $\mathrm{EC}_{50}$ result for each fungicide was as follow; $\mathrm{EC}_{50}$ for hexaconazole was in the range of 0.001 a. i. $\mu \mathrm{g} \mathrm{ml}^{-1}$ to 0.17 a. i. $\mu \mathrm{g} \mathrm{ml}^{-1}$; propiconazole from 0.001 a. i. $\mu \mathrm{g} \mathrm{ml}^{-1}$ to 0.47 a. i. $\mu \mathrm{g} \mathrm{ml}^{-1}$, and tebuconazole from 0.002 a. i. $\mu \mathrm{g} \mathrm{ml}^{-1}$ to 1.1 a. i. $\mu \mathrm{g} \mathrm{ml}^{-1}$.

Three $S$. homoeocarpa isolates that recorded the lowest $\mathrm{EC}_{50}$ value were selected as the representative sensitive strains, while five $S$. homoeocarpa isolates showing $\mathrm{EC}_{50}$ values greater than the isolates from golf course without prior history of fungicide application [(Sh14-2-1) by 20 times in hexaconazole, 50 times in propiconazole, and 35 times in tebuconazole] were selected as insensitive strains,

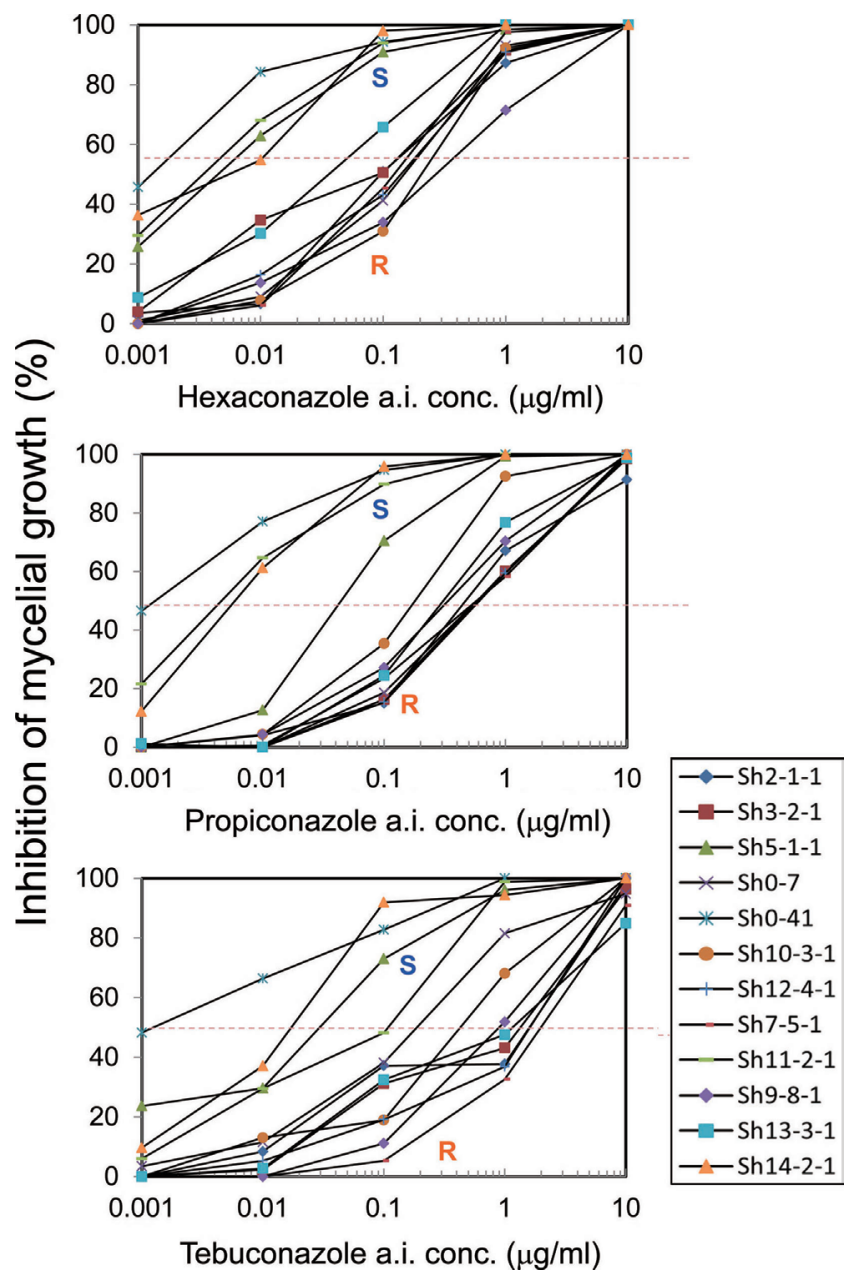

Fig. 2. Differential responses of twelve isolates of Sclerotinia homoeocarpa to hexaconazole, propiconazole, and tebuconazole. The isolates were grown on PDA amended with various concentrations of hexaconazole, propiconazole, and tebuconazole for two days at $25^{\circ} \mathrm{C}$ in darkness. Relative mycelial growth in $0.1 \mathrm{a}$. i. $\mu \mathrm{g} \mathrm{ml}^{-1}$ of each fungicide had a distinct gap between sensitive (S) and resistant $(\mathrm{R})$ isolates.

short listing a final selection of 12 strains in total (Table 3).

In the sensitive $S$. homoeocarpa isolates, the $\mathrm{EC}_{50}$ value was below $0.003 \mu \mathrm{g} \mathrm{ml}^{-1}$ for hexaconazole, $0.006 \mu \mathrm{g} \mathrm{ml}^{-1}$ for propiconazole, and $0.016 \mu \mathrm{g} \mathrm{ml}^{-1}$ for tebuconazole. $\mathrm{EC}_{50}$ value of insensitive strains was shown to be 50 times greater in hexaconazole, 50-70 times in propiconazole, and 77 times in tebuconazole (highest), compared to the sensitive isolates. On the concentration-reaction graph of the 12 selected isolates, hexaconazole, propiconazole, tebuconazole all showed distinguished inhibition rates in the concentration of $0.01 \mu \mathrm{g} \mathrm{ml}^{-1}$, with $50 \%$ inhibition rate at concentrations of $0.1 \mu \mathrm{g} \mathrm{ml}^{-1}$ (Fig. 2). Strains showing mycelial growth rates greater than $50 \%$ were 11 in hexaconazole among 66 isolates, 42 in propiconazole amongst 
Table 3. $\mathrm{EC}_{50}$ values and the $\mathrm{EC}_{50}$ ratio of resistant isolates $(\mathrm{R})$ to sensitive isolates $(\mathrm{S})$ of twelve selected isolates for each fungicide

\begin{tabular}{|c|c|c|c|c|c|c|c|}
\hline \multirow{2}{*}{\multicolumn{2}{|c|}{ Isolates }} & \multicolumn{2}{|c|}{ Hexaconazole } & \multicolumn{2}{|c|}{ Propiconazole } & \multicolumn{2}{|c|}{ Tebuconazole } \\
\hline & & $\mathrm{EC}_{50}$ & $\mathrm{R} / \mathrm{S}$ ratio $^{\mathrm{a}}$ & $\mathrm{EC}_{50}$ & $\mathrm{R} / \mathrm{S}$ ratio ${ }^{\mathrm{a}}$ & $\mathrm{EC}_{50}$ & $\mathrm{R} / \mathrm{S}$ ratio $^{\mathrm{a}}$ \\
\hline $\mathrm{S} 1$ & S0-41 & 0.002 & - & 0.001 & - & 0.004 & - \\
\hline $\mathrm{S} 2$ & Sh14-2-1 & 0.003 & - & 0.006 & - & 0.014 & - \\
\hline $\mathrm{S} 3$ & Sh11-2-1 & 0.003 & - & 0.005 & - & - & - \\
\hline S4 & Sh5-1-1 & - & - & - & - & 0.016 & - \\
\hline R1 & Sh9-8-1 & 0.169 & 49.1 & - & - & 0.526 & 36.5 \\
\hline $\mathrm{R} 2$ & Sh7-5-1 & 0.091 & 26.5 & 0.341 & 53.5 & 1.111 & 77.1 \\
\hline $\mathrm{R} 3$ & Sh2-1-1 & 0.092 & 26.7 & 0.451 & 70.8 & 0.670 & 46.5 \\
\hline R4 & S0-7 & 0.069 & 20.1 & 0.401 & 63.0 & - & - \\
\hline R5 & Sh12-4-1 & - & - & 0.401 & 62.9 & 0.556 & 38.6 \\
\hline R6 & Sh10-3-1 & 0.130 & 37.7 & - & - & - & - \\
\hline R7 & Sh3-2-1 & - & - & 0.426 & 66.9 & - & - \\
\hline R8 & Sh13-3-1 & - & - & - & - & 0.717 & 49.7 \\
\hline
\end{tabular}

${ }^{\mathrm{a}} \mathrm{R} / \mathrm{S}$ ratio was calculated as $\mathrm{EC}_{50}$ value $\left(\mathrm{a}\right.$. i. $\mu \mathrm{g} \mathrm{ml^{-1 }}$ ) of each resistant isolates divided by $\mathrm{EC}_{50}$ value of Sh14-2-1 which isolated from golf courses with no history of fungicides.

66 isolates, and 51 in tebuconazole amongst 66 isolates (Fig. 2).

Fungicide resistance distribution for each strain group was analyzed by indicating the value of resistance factor (RF), range of $\mathrm{EC}_{50}$ value, its mean with distinguished populations. Resistance Factor is a degree of increase in the fungicide resistance in comparison with isolate groups that were sensitive towards fungicides for there was no previous encounter reported early. Resistance factor was calculated by dividing the mean $\mathrm{EC}_{50}$ value of strain groups with decreased sensitivity towards fungicides with the mean
$\mathrm{EC}_{50}$ value of strain groups showing selective sensitivity from golf courses that had no history of fungicide. Groups, with greater RF value from 2.7 to 13.3 times than that of Sh14 strain groups which had no history of fungicide, were separated (Table 4).

Cross-resistance between triazole fungicides. As a result of pairwise comparison for determination of crossresistance of 3 triazole fungicides (hexaconazole, propiconazole, and tebuconazole), based on $\mathrm{EC}_{50}$ values from 66 isolates (Fig. 3), significant $(P<0.0001)$ relation coef-

Table 4. Range, mean $\mathrm{EC}_{50}$, and resistance factor (RF) for each fungicide in each population of Sclerotinia homoeocarpa from golf courses in Korea

\begin{tabular}{lccccccrccc}
\hline \multirow{2}{*}{ Population } & \multirow{2}{*}{ Isolates } & \multicolumn{3}{c}{ Hexaconazole } & \multicolumn{3}{c}{ Propiconazole } & \multicolumn{3}{c}{ Tebuconazole } \\
\cline { 3 - 10 } & & Range & mean & $\mathrm{RF}^{\mathrm{a}}$ & range & mean & $\mathrm{RF}^{\mathrm{a}}$ & range & mean & $\mathrm{RF}^{\mathrm{a}}$ \\
\hline Sh1 & 5 & $0.003-0.126$ & 0.054 & 9.4 & $0.025-0.263$ & 0.121 & 5.6 & $0.027-0.231$ & 0.123 & 3.0 \\
Sh2 & 4 & $0.011-0.092$ & 0.053 & 9.3 & $0.068-0.451$ & 0.263 & 12.1 & $0.089-0.653$ & 0.313 & 7.6 \\
Sh5 & 5 & $0.005-0.050$ & 0.027 & 4.7 & $0.046-0.210$ & 0.119 & 5.5 & $0.016-0.172$ & 0.128 & 3.1 \\
Sh6 & 3 & $0.027-0.049$ & 0.035 & 6.1 & $0.023-0.177$ & 0.093 & 4.3 & $0.054-0.344$ & 0.162 & 3.9 \\
Sh7 & 5 & $0.009-0.091$ & 0.035 & 6.1 & $0.015-0.341$ & 0.102 & 4.7 & $0.051-1.111$ & 0.352 & 8.6 \\
Sh8 & 4 & $0.020-0.037$ & 0.030 & 5.2 & $0.033-0.112$ & 0.071 & 3.3 & $0.053-0.194$ & 0.109 & 2.7 \\
Sh9 & 8 & $0.045-0.169$ & 0.070 & 12.3 & $0.067-0.257$ & 0.150 & 6.9 & $0.061-0.526$ & 0.272 & 6.6 \\
Sh10 & 5 & $0.029-0.130$ & 0.076 & 13.3 & $0.070-0.225$ & 0.131 & 6.0 & $0.150-0.345$ & 0.266 & 6.5 \\
Sh12 & 6 & $0.007-0.087$ & 0.042 & 7.4 & $0.036-0.401$ & 0.154 & 7.1 & $0.067-0.556$ & 0.181 & 4.4 \\
Sh13 & 5 & $0.020-0.076$ & 0.042 & 7.4 & $0.099-0.344$ & 0.249 & 11.5 & $0.126-0.717$ & 0.400 & 9.7 \\
Sh14 & 6 & $0.003-0.010$ & 0.006 & 1.0 & $0.006-0.052$ & 0.022 & 1.0 & $0.014-0.111$ & 0.041 & 1.0 \\
\hline
\end{tabular}

${ }^{a}$ Resistance factors were calculated as mean $\mathrm{EC}_{50}$ (a. i. $\mu \mathrm{g} \mathrm{ml}^{-1}$ ) of each population divided by mean $\mathrm{EC}_{50}$ of Sh14 population which isolated from golf courses with no history of fungicides. 

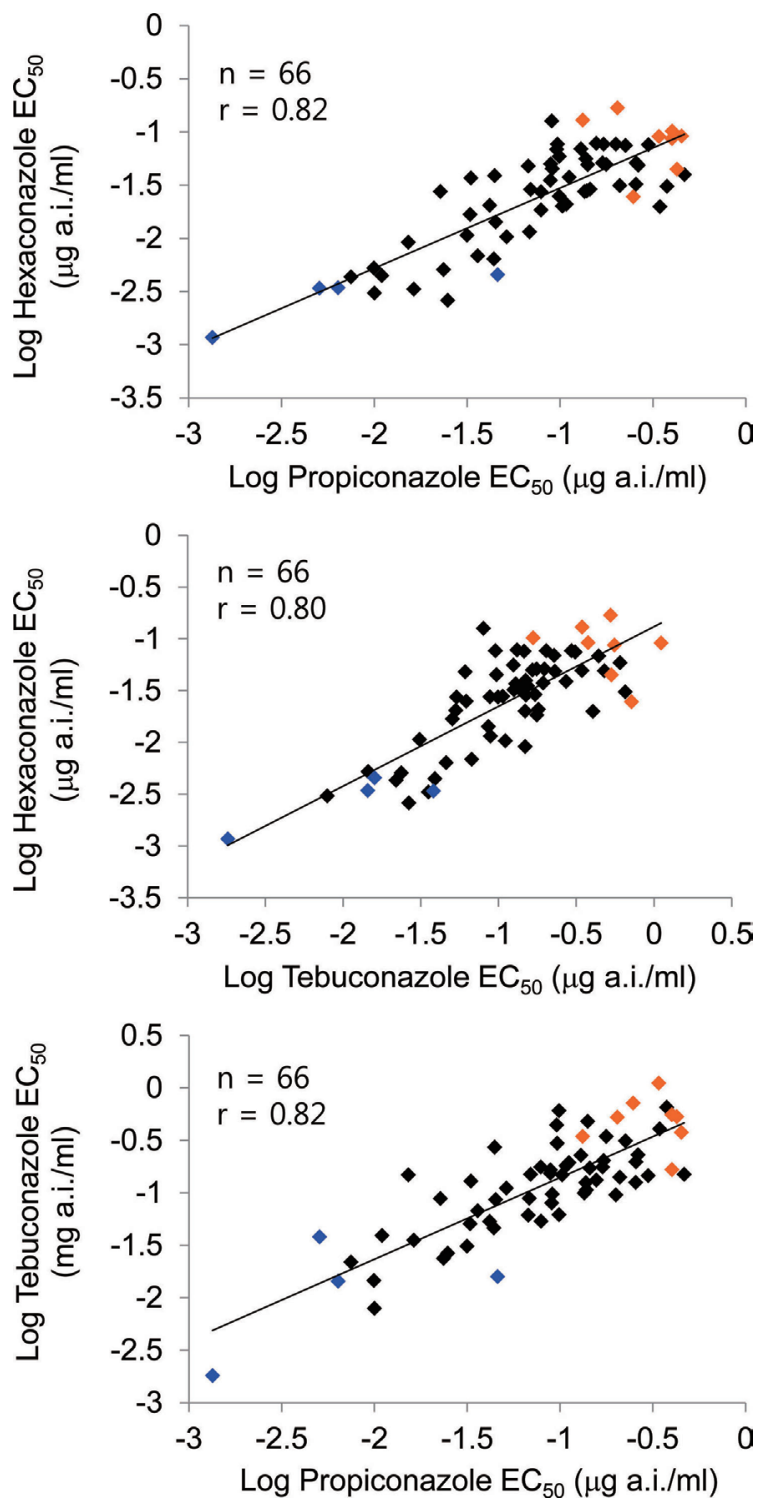

Fig. 3. Pairwise correlations of hexaconazole, tebuconazole, and propiconazole between $\log \mathrm{EC}_{50}$ values for 66 Sclerotinia homoeocarpa isolates including eight representative resistant isolates $(R$, red dot) and five representative sensitive isolates ( $S$, blue dot).

ficient $(r \geq 0.8)$, confirmed that cross resistance between hexaconazole, propiconazole, and tebuconazole was evident.

\section{Discussion}

Among the 10 golf courses from which S. homoeocarpa isolates were collected, 9 had a history of using more than one type of triazole fungicides, and Ecoland golf course had no history of using fungicides since its establishment, thus enabling base lining the sensitivity to the triazole fun- gicides. Baseline sensitivity is the standard sensitivity of the fungi towards the fungicide. Isolates with baseline sensitivity are useful in investigating and analyzing the degree of induction of resistance against the fungicide in certain strain groups, and differences in genetic composition of strains transited to resistance, and researching on genes related to fungicide resistance (Russell, 2004). Hsiang et al. (2007) researched on the distribution of baseline sensitivity in the $S$. homoeocarpa isolates before the registration and usage of triazole in all regions of Ontario, Canada, and all areas except for the ones along the borders of the United States, propiconazole showed $\mathrm{EC}_{50}$ value lower than 0.009 $\mu \mathrm{g} \mathrm{ml}^{-1}$ while tebuconazole showed mean $\mathrm{EC}_{50}$ value lower than $0.03 \mu \mathrm{g} \mathrm{ml}^{-1}$ in all groups. $\mathrm{EC}_{50}$ value of selected sensitive strains in this research lie within the $\mathrm{EC}_{50}$ range of representative sensitive strains obtained from golf courses that had no history of fungicide in Canada, United States, and others, thus showing the baseline sensitivity towards these triazole fungicides.

When analyzing the concentration reaction graph of 12 selected isolates, inhibition rates were evident at concentrations of $0.01 \mu \mathrm{g} \mathrm{ml}^{-1}$ for hexaconazole, propiconazole, and tebuconazole, and sensitive or resistant isolates could be distinguished (Fig. 2) based on the 50\% inhibition rates at concentrations of $0.1 \mu \mathrm{g} \mathrm{m}^{-1}$. Concentration of $0.1 \mu \mathrm{g}$ $\mathrm{ml}^{-1}$ is thus used as threshold concentration to distinguish between sensitive and resistant strains in earlier reports by Miller et al. (2002), Jo et al. (2006, 2008), and Popko et al. $(2012,2013)$. In this current work sensitive and insensitive strains could be distinguished at concentrations of $0.1 \mu \mathrm{g}$ $\mathrm{ml}^{-1}$ based on the $50 \%$ inhibition rate. Popko et al. (2012) used fungicides in 4 golf courses whereby the effectiveness of fungal prevention decreased after spraying of propiconazole, and infection appeared after 7 days. Separated isolates showed mycelium growth rates greater than 50\% in the determinant concentration $\left(0.1 \mu \mathrm{g} \mathrm{ml}^{-1}\right)$. Based on this result, Popko et al. (2013) reported that by marking the $50 \%$ of mycelium growth rate $0.1 \mu \mathrm{g} \mathrm{ml}^{-1}$, strain groups showing higher mycelium growth rate can easily be distinguished as strains indicating practical field resistance (PFR). In this research, strains showing mycelium growth rate of greater than $50 \%$ in the concentration of $0.1 \mu \mathrm{g} \mathrm{ml}^{-1}$ were 11 out of 66 strains in hexaconazole, 42 out of 66 strains in propiconazole, and 51 out of 66 in tebuconazole (Fig. 2), predicting greater occurrence of strains showing PFR in propiconazole and tebuconazole, also requiring further verification in field experiments.

As a result of pairwise comparisons between the 3 triazole fungicides, relation coefficient of greater than 0.8 was obtained, confirming cross-resistance. Relativity to 
tebuconazole-propiconazole showed the same results for the triazole fungicide as that of Miller et al. (2002), and in Colletotrichum cereale that causes plant anthracnose, tebuconazole and propiconazole showed significant correlation, indicating that there may be genuine correlation between the two fungicides (Wong and Midland, 2007). Further research on the genetic understanding of intersected resistance in aspect of genetic relation between triazole fungicides, could lead to a better understanding of this aspect.

Golembiewski et al. (1995) verified that the actual fungicide effectiveness decreased in groups showing RF values greater than 50 in propiconazole, and Burpee et al. (1997) reported that in propiconazole groups with RF values of 5.8, decrease in the effectiveness of fungicide was observed and the time taken for induction of disease was shortened following fungicide application. Miller et al. (2002) reported that with increasing $\mathrm{EC}_{50}$ values of propiconazole, the time taken for the reoccurrence of infection was significantly shortened, AUDPC (area under disease progress curve) and $\mathrm{EC}_{50}$ showed proportional correlation, and the insensitive strains showed significantly high AUDPC values. However, Jo et al. (2006) reported that in 10 regions of Ohio, the mean $\mathrm{EC}_{50}$ values ranged 0.082-0.171 $\mu \mathrm{g} \mathrm{ml}^{-1}$, showed the elevated $\mathrm{EC}_{50}$ value compared to the sensitive one but not decreasing the effectiveness of propiconazole. Hsiang et al. (2007) also stated that the PFR of group with $4.2 \mathrm{RF}$ value against propiconazole was not observed, but when injection experiments were conducted on selected sensitive $\left(\mathrm{EC}_{50}<0.01 \mu \mathrm{g} \mathrm{ml}^{-1}\right)$, moderately resistant $\left(\mathrm{EC}_{50}>0.01\right.$ $\left.\mu \mathrm{g} \mathrm{ml}^{-1}\right)$, and resistant $\left(\mathrm{EC}_{50}>0.1 \mu \mathrm{g} \mathrm{ml}^{-1}\right)$ strains, the time taken for less sensitive strains to exhibit the infection was shortened, showing significant difference in the number of symptom per pot after 2 weeks of fungicide usage. The precise $\mathrm{RF}$ and standard $\mathrm{EC}_{50}$ triggering $\mathrm{PFR}$ was required to be researched in relation with the actual effectiveness of the fungicide and sensitivity of strains in vitro.

Through this research, sensitivity of $S$. homoeocarpa isolates to triazole fungicides separated from 10 golf courses was identified, and the fungicide resistance of isolates was detected compared to control isolates taken from golf courses with no previous history of fungicide application. Further research on verification of PFR on actual field tests, based on in vitro results, and elucidating the mechanism of resistance induction by comparison of resistant strains and sensitive strains could prove beneficial towards a fundamental understanding of this research.

\section{Acknowledgments}

This work was supported by the 2014 Research Fund of the
University of Seoul.

\section{References}

Burpee, L. L. 1997. Control of dollar spot of creeping bentgrass caused by an isolate of Sclerotinia homoeocarpa resistant to benzimidazole and demethylation-inhibitor fungicides. Plant Dis. 81:1259-1263.

Cole, H., Taylor, B. and Duich, J. 1968. Evidence of differing tolerances to fungicides among isolates of Sclerotinia homoeocarpa. Phytopathology 58:683-686.

Detweiler, A. R., Vargas, J. M., Jr. and Danneberger, T. K. 1983. Resistance of Sclerotinia homoeocarpa to iprodione and benomyl. Plant Dis. 67:627-630.

Doney, J. C., Jr. and Vincelli, P. C. 1993. Cross resistance in Sclerotinia homoeocarpa to DMI fungicides. Phytopathology 83:1338 (Abstract).

Golembiewski, R. C., Vargas, J. M., Jr., Jones, A. L. and Detweiler, A. R. 1995. Detection of demethylation inhibitor (DMI) resistance in Sclerotinia homoeocarpa populations. Plant Dis. 79:491-493.

Hsiang, T., Liao, A. and Benedetto, D. 2007. Sensitivity of Sclerotinia homoeocarpa to demethylation inhibiting fungicides in Ontario, Canada after a decade of use. Plant Pathol. 56:500507.

Hsiang, T., Yang, L. and Barton, W. 1997. Baseline sensitivity and cross-resistance to demethylation-inhibiting fungicides in Ontario isolates of Sclerotinia homoeocarpa. Eur. J. Plant Pathol. 103:409-416.

Jo, Y.-K., Chang, S. W., Boehm, M. and Jung, G. 2008. Rapid development of fungicide resistance by Sclerotinia homoeocarpa on turfgrass. Phytopathology 98:1297-1304.

Jo, Y.-K., Niver, A. L., Rimelspach, J. W. and Boehm, M. J. 2006. Fungicide sensitivity of Sclerotinia homoeocarpa from golf courses in Ohio. Plant Dis. 90:807-813.

Leroux, P. 1992. Negative cross resistance in fungicides: from the laboratory to the field. In: Resistance '91 achievements and developments in combating pesticide resistance, eds. by I. Denholm, A. L. Devonshire, and D. W. Hollomon, pp. 179189. Elsevier Applied Science, London, UK.

Massie, L. B., Cole, H. and Duich, J. 1968. Pathogen variation in relation to disease severity and control of sclerotinia dollar spot of turfgrass by fungicides. Phytopathology 58:16161619 (Abstract).

Miller, G. L., Stevenson, K. L. and Burpee, L. L. 2002. Sensitivity of Sclerotinia homoeocarpa isolates to propiconazole and impact on control of dollar spot. Plant Dis. 86:1240-1246.

Mocioni, M., Gennari, M. and Gullino, M. L. 2001. Reduced sensitivity of Sclerotinia homoeocarpa to fungicides on some Italian golf courses. Int. Turfgrass Soc. Res. J. 9:701-704.

Ok, C.-H., Popko, J. T., Jr., Campbell-Nelson, K. and Jung, G. 2011. In vitro assessment of Sclerotinia homoeocarpa resistance to fungicides and plant growth regulators. Plant Dis. 95:51-56. 
Popko, J. T., Jr., Ok, C. H., Campbell-Nelson, K., Hulvey, J. and Jung, G. 2013. A qualitative assay for in vitro detection for potential propiconazole field resistance in isolates of the dollar spot fungus, Sclerotinia homoeocarpa. Int. Turfgrass Soc. Res. J. 12:103-109.

Popko, J. T., Jr., Ok, C.-H., Campbell-Nelson, K. and Jung, G. 2012. The association between in vitro propiconazole sensitivity and field efficacy of five New England Sclerotinia homoeocarpa populations. Plant Dis. 96:552-561.

Robbertse, B., Van Der Rijst, M., Van Aarde, I. M. R., Lennox, C. and Crous, P. W. 2001. DMI sensitivity and cross-resistance patterns of Rhynchosporium secalis isolates from South Africa. Crop Protect. 20:97-102.

Russell, P. E. 2004. Sensitivity baselines in fungicide resistance research and management. FRAC Monograph No. 3. GIFAP,
Brussels.

Shim, G. Y., Min, G. Y., Shin, H. D. and Lee, H. J. 2001. Occurrence of chemical resistance and control of dollar spot caused by Sclerotinia homoeocarpa in turfgrass of golf course. Kor. Turfgrass Sci. 15:1-8 (in Korean).

Vargas, J. M., Jr., Golembiewski, R. and Detweiler, A. R. 1992. Reduced sensitivity of Sclerotinia homoeocarpa to DMI fungicides. Phytopathology 82:1069 (Abstract).

Warren, C. G., Sanders, P. and Cole, H. 1974. Sclerotinia homoeocarpa tolerance to benzimidazole configuration fungicides. Phytopathology 64:1139-1142.

Wong, F. P. and Midland, S. L. 2007. Sensitivity distributions of California populations of Colletotrichum cereale to the DMI fungicides propiconazole, myclobutanil, tebuconazole, and triadimefon. Plant Dis. 91:1547-1555. 